Session 2563

\title{
Virtual and Real Forming of Sheet Metal - A Classroom Scenario
}

\author{
Raghu Echempati, William J. Riffe*, K. Joel Berry \\ Department of Mechanical Engineering \\ *Department of Industrial \& Manufacturing Engineering and Business \\ Kettering University \\ Flint, MI 48504
}

\begin{abstract}
This paper is concerned with the philosophy behind development of a new course Computer Simulation of Metal Forming Processes at Kettering University (formerly, GMI Engineering \& Management Institute) in Flint, Michigan. Kettering University has a unique undergraduate program that requires all students to go through a 5-year co-op experience beginning in the first year and a required fifth year thesis. In talking to several co-op company advisors and based on advising several fifth year thesis students for the past two years at Kettering University, it is becoming apparent that validation of virtual forming outcomes of intricate and complex sheet metal parts with real forming is rapidly gaining importance. This is particularly true in the early stages of product and process design, because of the high cost and time associated with real forming using hard tooling. Students working in this or similar virtual product and process design areas need to be trained in order to meet the demands of such industries. In a class room environment, however, the use of virtual forming is enhanced by demonstrating that the virtual process provides solutions very nearly identical to the real process. In order for the students to have instant feedback of virtual forming technology, real forming by use of hard tooling is necessary and crucial for their proper understanding of the forming process itself. It is believed that no other school offers a course coupling at the undergraduate level that combines both virtual and real forming. The ultimate goal of this course coupling is to bridge this gap. Initially, however, product and process design in the area of sheet metal forming is addressed.
\end{abstract}

Introduction

With the advent of high-speed computers, virtual design and optimization of manufacturing products and processes is becoming a reality. Many industrial establishments, particularly in the automotive sector, are turning towards virtual forming techniques in order to maintain competitiveness in today's world market. Virtual forming enables students and practicing engineers to study in detail the pattern and type of metal flow during a forming process. Use of "soft tooling" is gaining popularity compared to "hard tooling", particularly in the early stages of product and process design. Proper modeling, simulation and evaluation capabilities associated with soft tooling can make the entire forming process very cost effective by eliminating the need for building and testing numerous prototypes at various stages of the engineering design. There is growing demand 
for engineers trained in this area, as many companies engaged in metal forming research are turning towards virtual forming. Kettering University recently funded a grant proposal to procure a hydraulic press that has adaptive controls allowing experiments in non-circular forming and parametric studies that will facilitate the creation of real forming models for subsequent simulation. Another grant proposal is in preparation stage requesting funds to procure a dedicated high-speed computer server and terminals to support the virtual forming laboratory. As mentioned before, the objective of this paper is to share ideas on the philosophy of combining virtual and real metal forming technology.

Kettering University has offered a class on Sheet Metal Forming based on hard tooling and real forming processes for over forty years, and a new separate elective course on virtual metal forming using software tools is being prepared. While the real forming part of the course deals with performing laboratory experiments for validation and testing of simple formed parts; the virtual forming course emphasizes the parametric studies of the metal forming variables using the computer numerical simulation techniques. In the long term, these two courses will work together to provide industry with students trained in real and virtual metal forming processes in an applied manner. The goals and objectives of this course sequence follow the mission and goals of Kettering University in general, and the goals of the respective departments in particular. The overall university goal is to enhance the undergraduate and graduate education through hands-on education and to promote inter-disciplinary applied research activities.

The question is therefore raised: "Does concurrent coursework in real and virtual forming of sheet metal enhance the understanding of the technology of both fields?" This paper describes the beginning of an attempt to answer that question.

\section{Background}

The ME department consists of 38 full-time faculty and the IMEB Department has 29 faculty members, out of which 7 serve the Manufacturing Systems Engineering students. During the last two years, Mechanical Engineering Department initiated a reform effort that includes the integration of technology and design throughout the curriculum. The primary goal is to expose undergraduate students to high-end Computer Aided Engineering (CAE) software and design methodologies for virtual design and optimization. This focus resulted in the definition of several $21^{\text {st }}$ Century Core Technological Challenges (CTC). Two of these challenges are Manufacturing Engineering \& Micro Technologies in addition to Simulation Engineering \& MDO (MultiDisciplinary Design Optimization). The objectives and goals presented in this paper support the above CTC focus and will help faculty prepare students that understand industry's requirement for a reduction in the overall design cycle through the use of CAE tools for Virtual Design Manufacturing (VDM).

Rapid technological and economic changes within Mechanical and Manufacturing Engineering have left many colleges and universities hard-pressed to prepare graduates for the latest technical and managerial trends, as well as to impart the high-end CAE skills needed to serve society and industry. Some schools are rising to the challenge by developing interdisciplinary courses, pooling resources both within their university and with other academic institutions, and partnering with private industry and/or government to better prepare their students for the realities of professional 
engineering. Manufacturing and engineering companies around the world have begun to build virtual products and processes that can communicate across the barriers of time, distance, discipline, and culture.

In the metal forming area, these firms are finding that the return on investment from the application of virtual forming technology is one of the most exciting recent developments in computer simulation. So far, metal forming is still considered more of an art than science. This is due to the difficulty of transferring the forming technology into a knowledge database for proper parametric modeling and analysis using high-speed computational tools. Early adopters have already discovered that the integration of such software can enhance collaborative engineering, significantly reduce design-cycle time as well as the need for physical prototypes and models, and increase a product's ultimate market acceptance and penetration. While the usual CAD software is typically designed for non-real-time modeling, interactive simulation software such as LS-DYNA ${ }^{\circledR}$ along with pre- and post-processor software can produce real-time visualization and interaction of the results. The overall gains of this effort are based on the ability to involve a far greater number of students (and later engineers) who are involved in the design and manufacture of a product.

To accomplish some of these ideas, the developmental efforts focus on further enhancement and future integration of two courses that are currently offered at Kettering University. The MfgE-404 Sheet Metal Forming course is offered by IMEB Department (with ME-202: Mechanics of Solids and MfgE-370: Engineering Materials as pre-requisites), and ME-510 Computer Simulation of Metal Forming Processes (with MfgE-370, ME-315: Computer Aided Engineering and ME-342: Advanced Solids as pre-requisites, and possibly ME-429: Finite Elements as co-requisite). Catalog description of these courses is outlined in Appendix 1.

Itemized objectives of the detailed plan

I. Enhancement of the existing Sheet Metal Forming course

(i) upgrade the existing stamping laboratory by procuring a hydraulic press and the accompanying controls and tooling

(ii) prepare a set of experiments in the redraw and reverse redraw of simple parts

(iii) develop the necessary press and tooling data to generate Forming Limit Diagrams for different materials such as a variety of steels, aluminum and other materials

(iv) prepare handouts and laboratory manual that includes all of the experiments in the metal forming area

(v) upgrade the existing laboratory experiments and class notes

II. Enhancement of the existing Computer Simulation of Metal Forming course

(i) upgrade the existing CAE laboratories by procuring a high speed computer server such as the Sun Enterprise 3500 with enough memory capacity and $70^{+}$GB of disk space to educate more students and for the thesis students to run simulation of some of the actual sheet metal parts from their co-op companies

(ii) develop handouts, class notes and computer laboratory manual

(iii) to enhance faculty research in virtual forming and support the integration of applied research into the undergraduate curriculum

(iv) introduce the virtual and real forming courses at the graduate level 
Of the above two courses, the MfgE-404 is well established that has both lecture and hands on laboratory content. The class size is around 40 per term and it is offered during Winter and Spring terms. Some of the students taking this class work in the sheet metal forming area for their co-op company and quite often they choose their thesis topic in this area. The laboratory requires students to work in groups of 3 to 5 with either 4 or 5 groups per lab section. Because of the high number of students in the class, multiple lab sections are required. The experiments are designed to be openended with a prescribed sequence of operations to follow but no indication of where the experiment will terminate except to say that all experiments are pushed until the tooling has been exhausted or the material fractures. The experiments are divided into three categories: material properties for sheet metal forming; draw tooling where the effects of die entry radius, punch nose radius, punchto-die clearances and attendant press signatures are examined, and hole expansion; and other processes such as stretching, bending, and lubrication. A small hand-operated press provides limited opportunity to demonstrate redrawing and reverse redrawing. A sufficient supply of different steels is used so that the material effects are also considered in most experiments. Laboratory reports detail the experiment, the observations, pertinent calculations of strain and tooling interactions, and other conclusions reached by the team. Figure 1 in Appendix 2 shows examples of stamped parts in this laboratory. As mentioned above, the current mechanical press would require extensive modifications and tooling to study redraw and reverse redraw situations and to control the load and depth ranges to investigate other geometric effects.

Some of the above mentioned difficulties are partially addressed in the ME-510 course by conducting several LS-DYNA ${ }^{\circledR}$ runs with the different forming parameters varied. This course is also offered during Winter and Spring terms. Lecture classes cover the introductory theory required to understand the applications of nonlinear material properties (plasticity) and nonlinear finite element analysis to the modeling and simulation of large deformation problems in metal forming. Some of the computational issues like the hourglass modes and stability are also discussed and demonstrated on the computer. Appendix 3 shows the detailed outline, learning outcomes and learning objectives of the ME-510 course.

The students start off by observing the one-step (Quikstamp ${ }^{\odot}$ or FastForm $3 \mathrm{D}^{\odot}$ ) and the incremental $\left(\mathrm{LS}_{\mathrm{DYNA}}{ }^{\odot}\right.$ ) results of example problems that are provided by these software companies. Due to computer resource limitations, they then attempt to simulate simple problems following the tutorials provided to them. For their project, students attempt to perform parametric studies to simulate the bending and drawing operations that are done in the MfgE-404 laboratory. Fig. 2 in Appendix 2 shows results of a simple example of a cup draw using the Quikstamp ${ }^{\odot}$ onestep solver. These results are for quarter-symmetry model of a full cup drawn in the sheet metal laboratory that show the geometry of the tooling, metal flow in the circumferential and radial directions, and thinning in the $\mathrm{z}$ direction. Also, forming limit diagrams (FLD) can be obtained as shown to understand the drawbility of parts. As mentioned earlier, the corresponding incremental solution for this model takes much longer time than the one-step solution. However, the incremental solution gives more predictable and step by step results that are required especially for non-circular or asymmetric problems. The biggest draw back at the present time is the limitation on the computational power in terms of the computer speed and the available disk space per student. This keeps the class size to fewer than ten students per term. Although it may be possible to conduct the simulation laboratory as a demonstration laboratory, the student background and co-op 
education at Kettering University requires more hands-on experience. Moreover, it is desirable for the students working in the stamping area for their fifth year thesis to run simulation of real parts while they are on campus. Some of the recent students's thesis titles are given in Appendix 4.

\section{Evaluation and dissemination tools}

Initially, some of the commonly adopted assessment tools will be used either in person or via email or through Internet. These are: on campus tests, homework, laboratory reports and papers written out of thesis work, student surveys, alumni survey, industrial participant survey. For dissemination of results, once again, some of the commonly used tools will be used. These are: presentation of technical papers in conferences (for example, ASME and ASEE), technical seminar and/or workshop presentations, continuing education to part-time students and practicing engineers, seminar/demonstration/poster-sessions for high school students through ASME/SME organizations during Engineers week and on "Discover Kettering University" Day, conducting a stamping symposium on campus, and finally, development of web page and internet access to lecture materials and simulations.

\section{Conclusions}

This paper outlines the philosophy and development of a new course Computer simulation of metal forming processes at the undergraduate level, and to see how a course coupling between the real and virtual sheet forming in the metal forming area may benefit the training of future engineers in this area. Although the goals and objectives presented here address the product and process design issues related to sheet metal forming, these objectives would be extended to metal forming area in general.

\section{Bibliography}

1. Valenti M., “Teaching tomorrow's engineers,” ASME Mechanical Engineering Magazine, V118/No.7, July 1996, pp 64.

2. Deitz D., "Re-engineering virtual prototypes," ASME Mechanical Engineering Magazine, V119/No.9, September 1997, pp 76.

3. Ghee S., "The virtues of virtual products," ASME Mechanical Engineering Magazine, V120/No.6, June 1998, pp 60.

4. Persun T., "Design analysis power on the PC," Integrated Manufacturing Solutions, SME Manufacturing Engineering Magazine, March 1999, pp 10.

5. Altan T., Oh S., and Gegel H., "Metal Forming: fundamentals and applications," Pub. American Society of Metals, 1983.

6. Kobayashi S., Oh S., and Altan T., "Metal forming and the finite element method," Oxford University Press, 1989.

8. Hallquist J., and Reid J., "LS-DYNA User's Manual, and Examples Manual” Livermore

Software Technology Corporation, 1998.

9. Proceedings of LS-DYNA User's Conference, 1996, 1997 and 1998 published by LSTC.

10. Hosford W., and Caddell R., "Metal Forming: Mechanics and Metallurgy," Prentice-Hall.

11. Internet web pages of some of the following Universities and Companies visited/contacted:
a. The Ohio State University, Columbus, OH., www . osu . edu
b. University of Michigan, Ann Arbor, MI., www. umich.edu
c. Michigan State University, East Lansing, MI., www . msu .edu
d. Washington State University. Pullman. WA., www.wsu . edu 
e. Wichita State University, Wichita, KS., www.wichita.edu

f. University of Nebraska-Lincoln, NB., www . uneb.edu

g. KBS2, Inc., Burr Ridge, Illinois., www. kbs2 . com

h. LSTC, CA., www . Istc. com

i. Engineering Technology Associates, Troy, MI., www.eta.com

j. Engineering Systems Incorporated, Troy, MI.

k. Forming Technologies, Inc., www. fti.com

\section{Biography}

Raghu Echempati is currently an assistant professor at Kettering University (formerly, GMI Engineering \& Management Institute). He received his undergraduate degree from Andhra University, Waltair (India) and his Master of Technology and $\mathrm{Ph}$. D. from the Indian Institute of Technology, Kharagpur (India), all in the field of Mechanical Engineering. He was a post doctoral research associate (NSF funded) with late Professor George N. Sandor at the University of Florida, Gainesville, Florida in 1979. He later worked at several Universities, including the Indian Institute of Technology, The Ohio State University, Washington State University, Michigan Technological University and The University of Mississippi. Raghu Echempati is a registered professional engineer in the State of Mississippi, and a certified manufacturing engineer issued by the Society of Manufacturing Engineers. He has several research publications in the areas of Dynamics, Mechanisms, Vibrations and Manufacturing. He is a member of ASME, ASEE, SAE, and SME.

William J. Riffe Professor is currently a professor at Kettering University. He received his undergraduate degree from the University of Cincinnati and his Master of Science and Ph. D. from Carnegie Institute of Technology, all in the field of Civil Engineering. He is a registered engineer in the State of Ohio. Prior to joining Kettering University he worked at U.S.Steel Corp. as a design specialist serving as a consultant to their customers nationwide in the field of sheet metal component design, material selection, and fabrication. This work encompassed all industries, including military. During his tenure, he was granted three patents for design applications. Concurrent with his tenure at U.S.Steel, he spent two years in the US Army Corps of Engineers as an officer with responsibility for over two million dollars of construction at a remote location on the Asian subcontinent. For his work there, he received the Army Commendation medal. Riffe has published widely technical papers in SAE, ASAE, and PMA. In addition to publishing, he conducts seminars for PMA annually and participates in several of their annual conferences. He is a member of SME, PMA, ASEE and FMA.

K. Joel Berry is currently the Head of Mechanical Engineering Department at Kettering University. He graduated from GMI with an undergraduate in Mechanical Engineering and joined General Motors soon after his graduation. He then did his M.S. from Michigan State University and Ph. D. from Carnegie Melon University. He worked at Westinghouse Research laboratories prior to joining GMI. His areas of expertise include CFD and Design Simulation \& Optimization. He has published several research papers in these areas. Professor Berry is a registered professional engineer in the State of Michigan, and is member of ASME, ASEE, SAE and $\Sigma X$. 
Appendix 1: Course Descriptions

\begin{tabular}{|c|c|c|}
\hline Course Number & Title & Enrollment/Year \\
\hline MfgE-101 & Manufacturing Processes & $500-600$ \\
\hline MfgE-404 & Sheet Metal Forming & $70-80$ \\
\hline ME-342 & Advanced Mechanics of Solids & $80-90$ \\
\hline ME-510 & Computer Simulation of Metal Forming Processes & $10-25$ \\
\hline ME-429 & Finite Element Method & $100-125$ \\
\hline
\end{tabular}

\section{MfgE-101: Manufacturing Processes}

This course is a survey of manufacturing processes with emphasis on technology and terminology, process principles and capabilities, material selection and comparative advantages and disadvantages. The material coverage includes metal and polymer properties and structure, casting, powder metallurgy, large deformation processes, joining, metal removal and measurement.

\section{MfgE-404: Sheet Metal Forming}

This course deals with the study of principles and processes of forming sheet metal using presses and tooling. The emphasis is on steel metal forming. Some of the topics include material properties, blanking, bending, drawing, stretching, stretch-draw, ironing and defects in sheet metal operations. Other topics such as part strain analysis includes strain circle evaluation and forming limit diagrams. The accompanying laboratory exercises on a single action press verify concepts covered in the classroom. Prerequisites: ME-202: Mechanics of Solids and MfgE-307: Engineering Materials.

\section{ME-342: Advanced Mechanics of Solids}

Analysis of stress and strain in three dimensions, torsion of thin-walled members, shear flow, analysis of thin- and thick-walled cylinders, curved beams, contact stresses energy methods, stability analysis, material properties and failure theories. Prerequisites: ME-202: Mechanics of Solids.

\section{ME-510: Computer Simulation of Metal Forming Processes (see Appendix 4 for a detailed course syllabus)}

The aim of this course is to introduce some of the latest techniques for modeling surface and bulk deformation processes through computer simulation. These simulations include sheet metal forming operations, rolling, swaging and other large deformation processes. Modern high-speed computer aided design technology is introduced here to study the behavior of the material during metal forming process, including the study of the strain pattern. Standard one-step and incremental software such as Quikstamp ${ }^{\circledR}$, FastForm $^{\circledR}$ and LS-DYNA ${ }^{\circledR}$ will be used for the course. These solution procedures will be discussed with emphasis on techniques in an applied manner.

Prerequisites: ME-202: Mechanics of Solids, ME-315: Computer Aided Engineering.

\section{ME-429: Finite Element Method}

One-, two- and three-dimensional simple elastic deformation problems of stress and strain, axisymmetric problems, beams and frames, pre- and postprocessing applications to the solution of heat transfer and fluid flow problems using computer software. Prerequisites: ME-202: Mechanics of Solids, ME-309: Vibrations. 
Appendix 2: Results from Sheet Metal Lab and Quikstamp

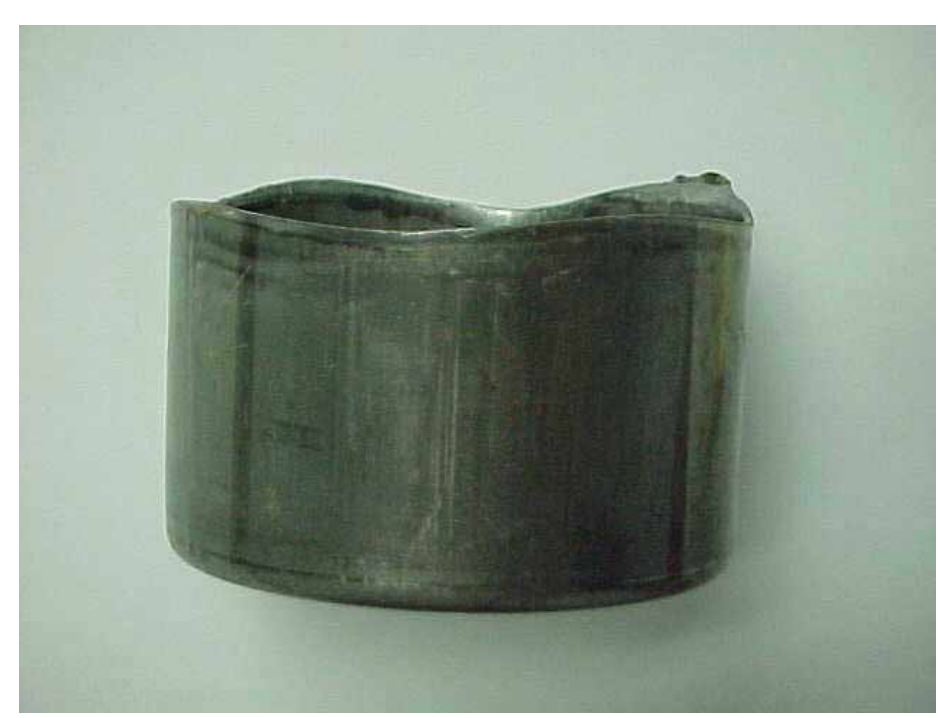

Eared cup

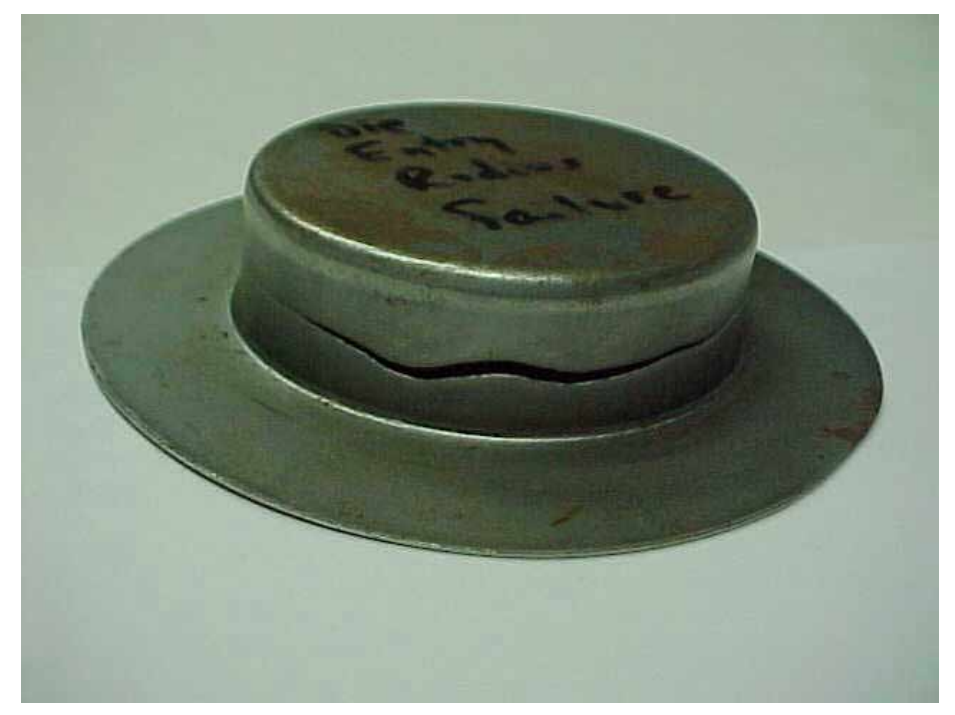

Die entry radius failure

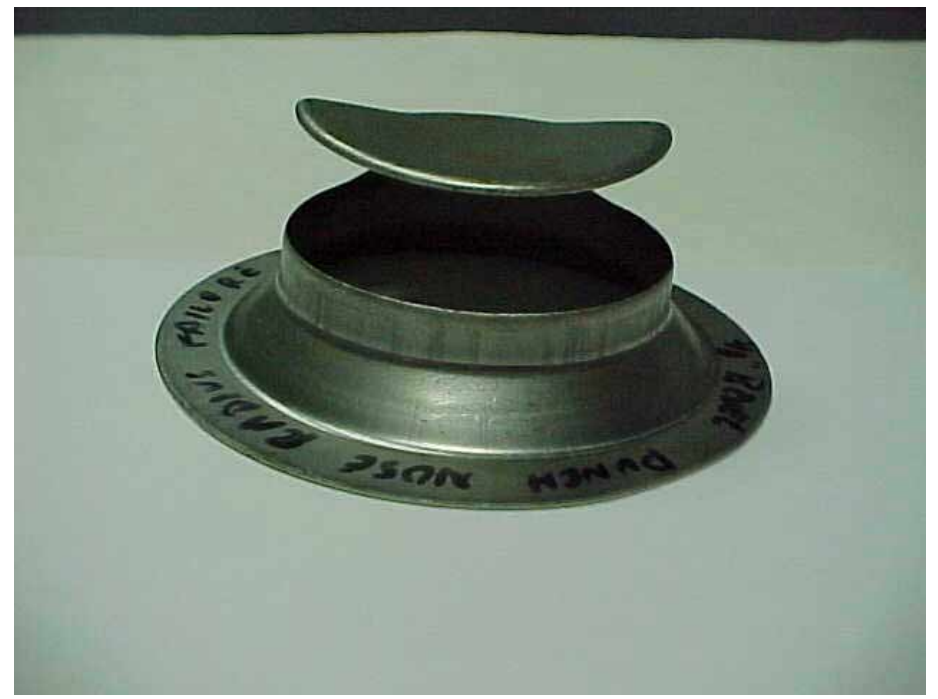

Punch nose radius failure

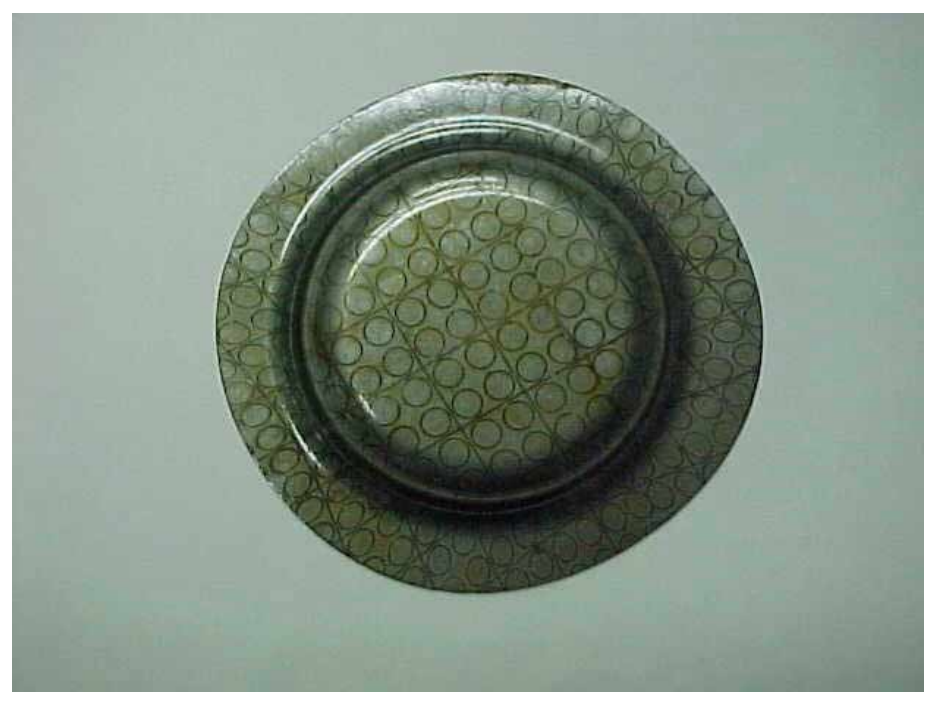

Gridded blank to visualize strain

Fig. 1 Example of stamped cups 
Fig 2: Example of Quikstamp ${ }^{\odot}$ Results

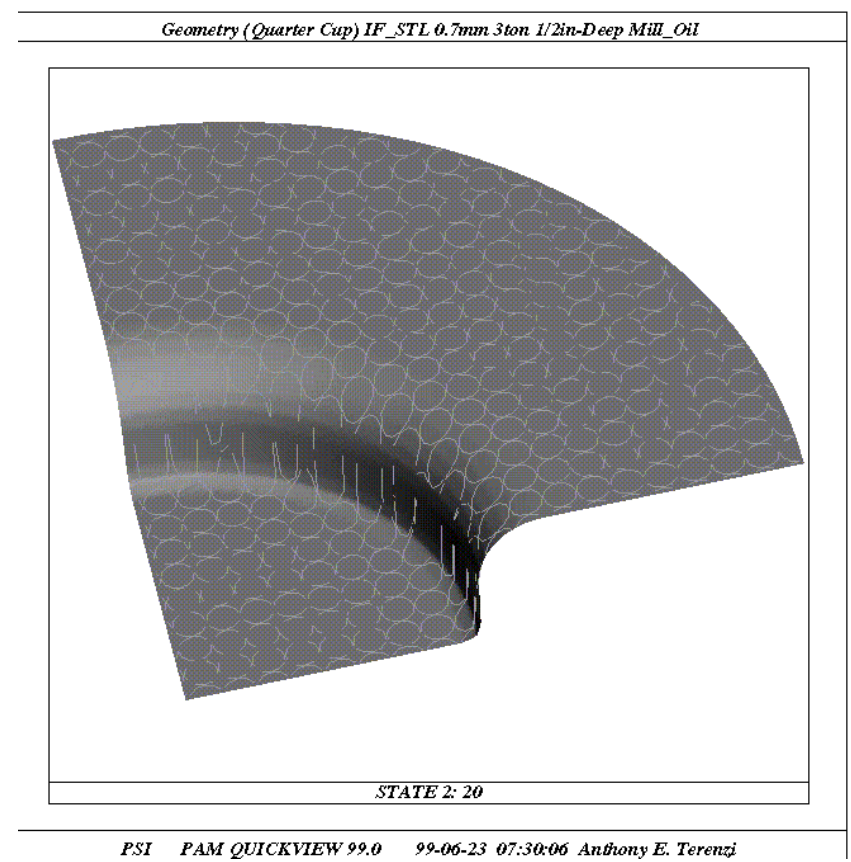

a) Geometry of the quarter model cup

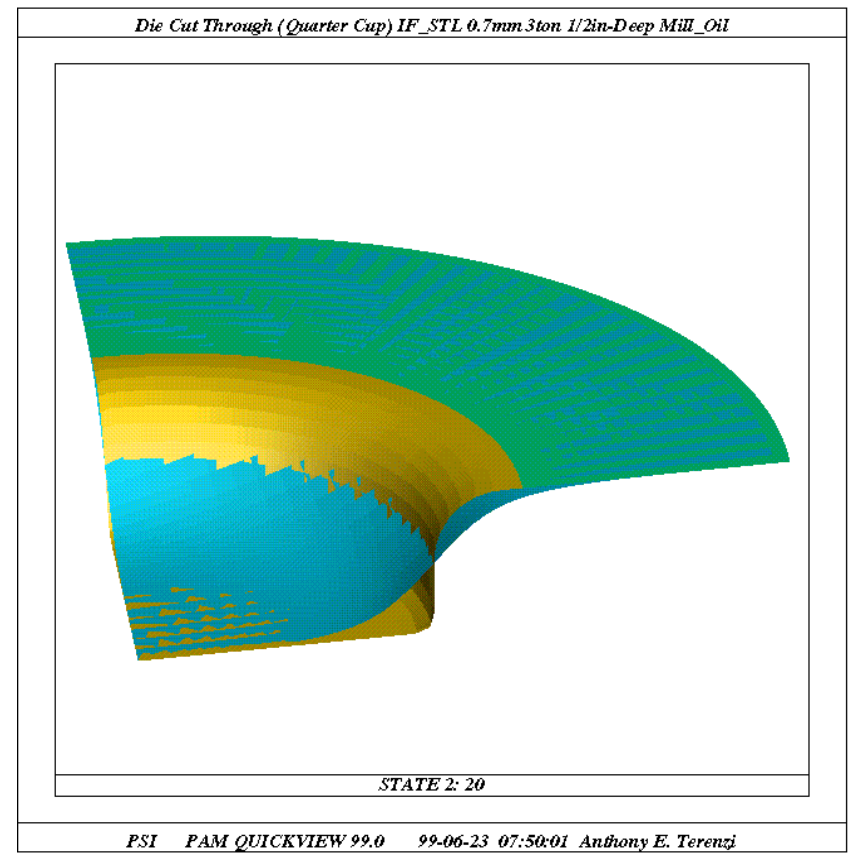

b) Wrong draw simulation result showing the cup cutting through the die 


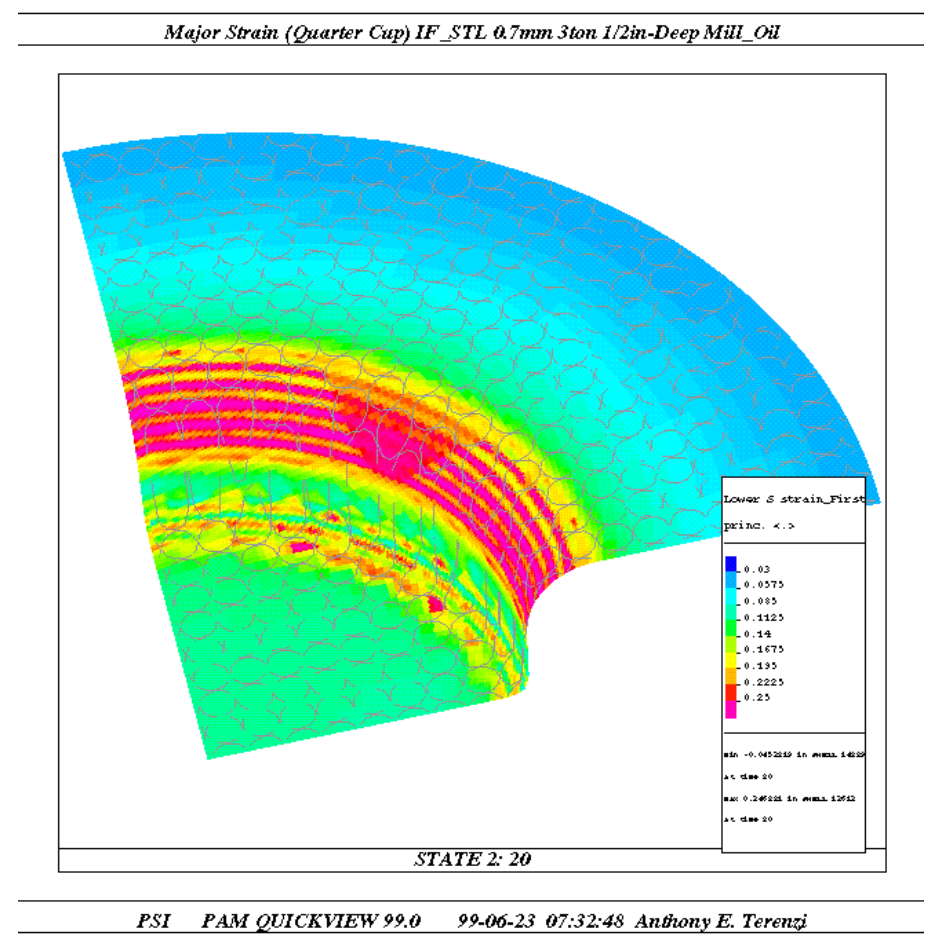

c) Major strain distribution in the quarter cup model

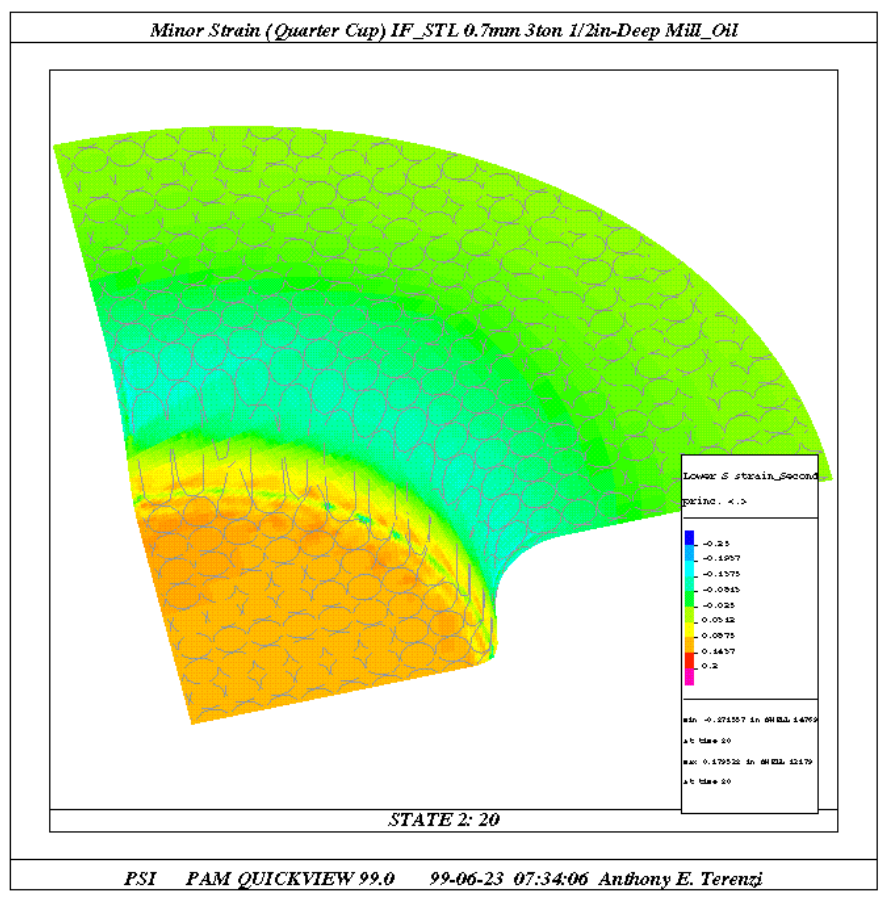

d) Minor strain distribution in the quarter cup model

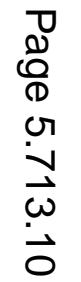




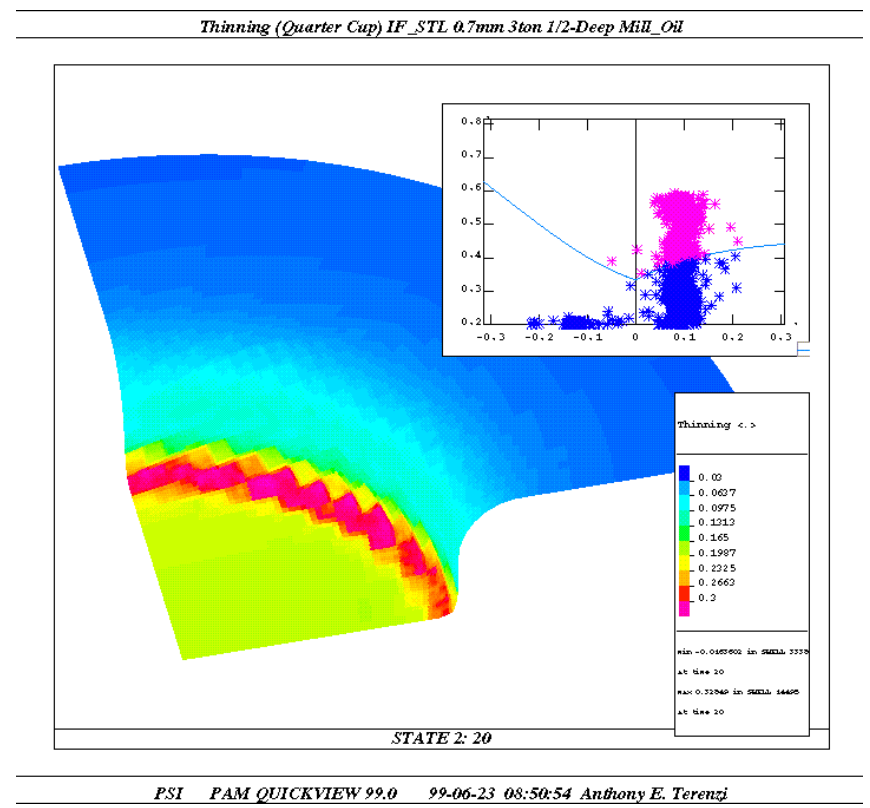

e) Results showing the thinning of the cup model with FLD curves

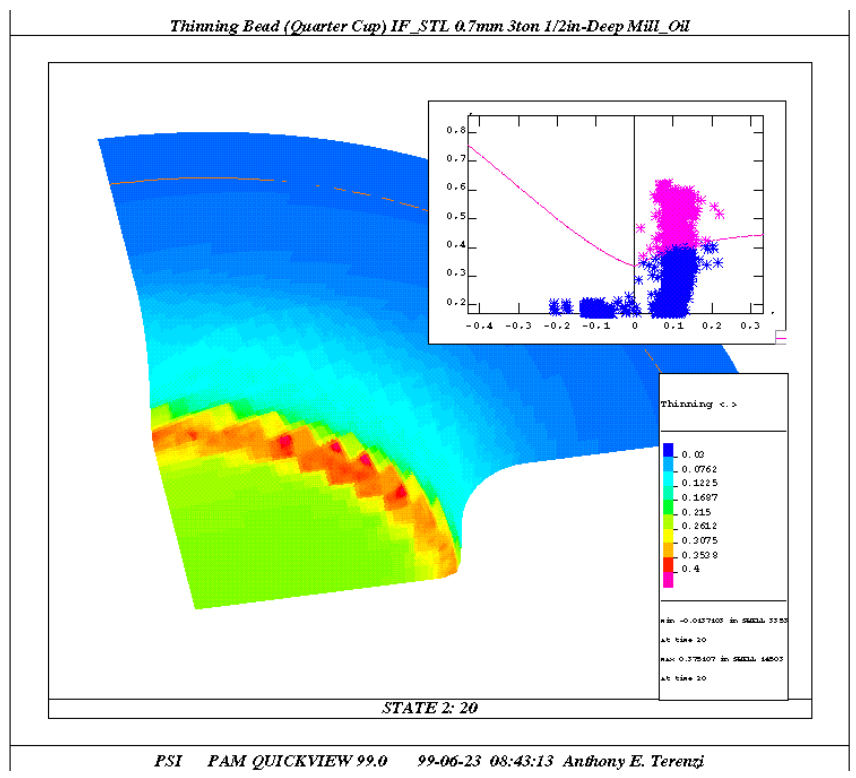

f) Thinning results showing the FLD with bead force

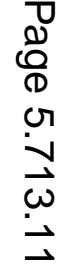




\section{Appendix 3 \\ Course Description \\ ME-510: Computer Simulation of Metal Forming Processes (2-4-4)}

Catalog Data: ME-510: Computer Simulation of Metal Forming Processes. 4 Credits (2 Lectures, 2 two-hour laboratories; 6 total contact hours). The main aim of this course is to introduce some of the latest techniques for modeling surface and bulk deformation processes through computer simulation. These simulations include sheet metal forming operations, or rolling, swaging and large deformation processes. Modern high-speed computer aided design technology is introduced here to study the behavior of the material during metal forming process, including the study of the strain pattern during the metal forming process. Standard one-step and incremental software such as Quikstamp ${ }^{\circledR}$, FastForm ${ }^{\circledR}$ and LS-DYNA ${ }^{\circledR}$ will be used for the course. These solution procedures will be discussed with emphasis on techniques in an applied manner.

\section{Prerequisites by Topics:}

1. Ability to understand and solve problems dealing with basic manufacturing processes and engineering materials.

2. Ability to model and solve problems dealing with strength and design of rigid bodies and machine components.

3. Ability to use a CAD software for computer visualization, solid modeling and design communication.

Textbook: $\quad$ None required

Reference: William F. Hosford and Robert M. Caddell, Metal Forming - Mechanics and Metallurgy, PrenticeHall, Inc. $2^{\text {nd }}$ Edition, 1995.

Tylan Altan, Soo-Ik Oh and Harold L.Gegel, Metal Forming - Fundamentals and Applications, American Society for Metals, 1992.

Quikstamp $^{\circledR}$, FastForm $^{\circledR}$ and $\underline{\text { LS-DYNA }}^{\circledR}$ Lab manuals.

N.M. Wang and S. C. Tang (editors), Computer Modeling of Sheet Metal Forming Process, The Metallurgical Society, Inc., 1985.

S. R. Reid, Metal Forming and Impact Mechanics, 1995.

Coordinator: Raghu Echempati

\section{Educational Outcomes:}

The educational outcome of this course is to teach students to integrate the principles of manufacturing processes, concepts of engineering materials, stress-strain behavior, plasticity, solid modeling and finite element analysis and simulation for large deformation of sheet metal parts. The design simulation includes understanding of deformation pattern and strain behavior of 3D sheet metal parts and an ability to understand and interpret the results. This course will use automotive and other real-world industrial applications to extend fundamentals introduced in Manufacturing Processes, Engineering Materials, Solid Mechanics, and CAE to perform virtual simulation of sheet metal parts.

Other topics such as rolling, forging and extrusion will also be discussed. Modeling and meshing issues in FEM will also be covered. Deformation behavior of axisymmetric and nonsymmetrical sheet metal parts will be discussed.

CAE tools such as I-DEAS ${ }^{\odot}$, DYNAFORM $^{\odot}$ and Quikstamp ${ }^{\odot}$ will be used to perform the modeling and analysis. Several practical design projects will be assigned during the term of this course.

\section{Educational Objectives:}

Objective 1: $\quad$ To enable the student to learn fundamentals of computer simulation of metal forming processes.

Objective 2: To increase the student's understanding of the benefits of virtual forming and its consequences on the early stages of a product design.

Objective 3: To introduce some of the latest techniques for computer modeling of bulk deformation processes. 
Objective 4: To increase the student's understanding of the behavior of metal flow during the metal forming process.

Objective 5: To enhance the student's critical understanding of the obstacles to accurate computer simulation of the metal forming process in an applied manner.

Objective 6: To enhance the student's understanding and correct interpretation of the results of a simulation and to develop strategies to improve the product and process design based on the results obtained.

Objective 7: To allow students to understand and appreciate the benefits of virtual forming.

[Note: $\quad$ These objectives refer to the Mechanical Engineering program objectives that will map in to the overall ABET 2000 A-K, and Mechanical Engineering L-R, learning outcomes.]

Topics:

- Introduction to various bulk deformation processes

- Basics of sheet metal formability

- Some practical considerations

- Benefits of simulation of bulk deformation processes

- Introduction to finite element analysis

- Numerical methods for finite element analysis

- Introduction to implicit versus explicit integration schemes and computer codes

- Pre- and Postprocessing $\left(\right.$ HyperMesh $^{\circledast}$ or DYNAFORM ${ }^{\circledast}$ ), and solving $\left(\right.$ LS-DYNA $^{\circledR}$ or Quikstamp $^{\circledast}$, or FastForm $^{\circledR}$ ) software

- Interpreting the results to get useful information

\section{Computer Usage:}

Unix or Windows $\mathrm{NT}^{\circledR}$ based software installed on metruck and/or megalaxy servers, and/or Windows $\mathrm{NT}^{\circledR}$ server will be used.

\section{Design Project:}

Each student is either assigned a computer simulation project by the professor, or is allowed to select a project of interest to their sponsors. The project should involve performing the simulation of a surface or bulk deformation process by varying the different design and process variables. The outcome of the project should provide valuable information about the product and process design in the early stages of a manufacturing product design. Also, the study should provide guidelines about the process capability based on interpreting the output stress, deformation and strain histories of the final product.

\section{Proposed Software and Laboratory:}

Preprocessor: $\quad$ Unix-based DYNAFORM ${ }^{\circledR}$ (Finite Element Model Builders of LS-DYNA ${ }^{\circledR}$ ) and Quikstamp that are installed on the metruck/galaxy servers will be used.

Solver: $\quad$ Quikstamp $^{\circledR}$ and LS-DYNA ${ }^{\circledR}$

Postprocessor: $\quad$ Unix based DYNAFORM ${ }^{\circledast} / \mathrm{NIKE} \mathrm{D}^{\circledR}$ and Quikstamp that are installed on the metruck/megalaxy servers will be used.

\section{Estimated ABET Category Content:}

Mechanical Engineering: 4 credits Design Credits: 2 credits 


\section{Appendix 4}

Since all the students at Kettering University must complete a fifth year thesis that is coordinated between their respective industrial sponsor and Kettering University, the possible extent of these student applied research for this paper is unlimited and ongoing. The following are the sample theses related to metal forming area in the past two years.

1. Jeremy J. Norwood, "The Use and Implementation of Sheet Metal Forming Simulation,”

L \& W Co., fifth year thesis (graduation in June 2000).

2. Anthony Terenzi, "Comparison and Evaluation Between One-step and Multistep Codes for Finite Element Analysis for Metal Stamping Simulation," Modern Engineering, fifth year thesis (graduation in June 2000).

3. Sanjeev Srinivasan, "Simulation of Swaging Metal Forming Process," M.S. student thesis project (1999).

4. Chad Stein, "Verification and Evaluation of the Simulation Process," Synergis Technologies, fifth year thesis (graduation 1999).

5. David True, "Feasibility and Product Design Knowledge Base for Hydroform Process," Tenneco, Walker Manufacturing, fifth year thesis (graduation 1999).

6. Sarang Likhite, "Spring back studies on Steel and Aluminum parts," M.S. student thesis in progress. 